\title{
Effect of Powder Mixed Dielectric fluid on Surface Integrity by Electrical Discharge Machining of RENE 80
}

\author{
A.Sugunakar ${ }^{1}$, A.Kumar ${ }^{2}$, R.Markandeya ${ }^{3}$ \\ ${ }^{I}$ Associate Professor in Mechanical Engineering Department, JITS, Warangal(R), T.S, India-506332; \\ ${ }^{2}$ Associate Professor in Mechanical Engineering Department, NIT Warangal \\ ${ }^{3}$ Professor in Metallurgical Engineering Department, JNTUH
}

\begin{abstract}
This paper mainly focussed to investigate the formation of Recast Layer and surface integrity of RENE 80 Nickel Alloy during powder mixed electrical discharge machining (PMEDM) process. The experiments were conducted considering electrical parameters (pulse on time, peak current and pulse off time) at optimal combination by varying powders like aluminium, graphite and combination of aluminium and graphite powders and their concentrations. The experimental results reveal that reduction in Recast Layer Thickness (RLT) with addition of powders into dielectric fluid. The minimum recast layer thickness (RLT) (14.42 $\mu \mathrm{m})$ was observed at aluminium powder concentration of $9 \mathrm{~g} / \mathrm{l}$ added in to the dielectric fluid. It was observed from the surface topography using scanning electronic microscope (SEM) micrographs that, with increase of powder concentration into the dielectric medium, increasing in crater depth and diameter. Thick appendages were found around the periphery of crater may be due to resolidified molten metal. The presence of oxygen and carbon elements was observed on machined surface from the EDAX analysis.
\end{abstract}

Key words: PMEDM, Aluminium Powder Concentration, Graphite Powder Concentration, Combination of Aluminium and Graphite Powders, RLT, SEM and EDAX.

\section{Introduction}

In EDM, erosion of two electrically conductive materials will occurs by instigation of recurring and continuous spark discharges in a small gap separated them. The melting of work piece will happen when sufficient heat is generated by the each electric spark also some tool material melts. The resistance increases due to evaporation of dielectric in the arc gap till interruption of arc takes place. The current flow between electrodes produces debris which is flushed out by the fluid. This can be done continually to erode a finely controlled element that would be unattainable to machine with traditional machining methods. However certain defects like porosity, residual stress and micro cracks in the recast layer due to enormous temperature followed by sudden cooling are usually found on the machined surface.

The wide applications and usage of this process made many manufacturing research engineers to confer more attention into the fundamentals of this process to enhance the process capabilities and applications. Erden and Bilgin [1] have first studied the effect of additive powders (copper, aluminium, iron, and carbon) mixed in dielectric fluid (kerosene) on EDM of brass-steel and copper-steel pair. It was noticed that machining rate increases with increase in concentration of powder. However, it was reported that machining becomes unstable at excessive concentration of abrasive particles due to occurrence of short circuits. Guo $\mathrm{Z} \mathrm{N}$ et al[2] have reported the similar results during electrical discharge machining of tungsten carbide with addition of fine aluminium powder into kerosene. Zhao et al [3] reported on the powder mixed EDM during rough machining. It was observed that increase in machining efficiency of PMEDM by selecting proper discharging parameters. Singh et al [4] out experimental investigation on powder mixed EDM on cast aluminium metal matrix composite (MMC) ( $\mathrm{Al} / \mathrm{Al}_{2} \mathrm{O}_{3}$ p-20\%) adding silicon carbide powder in dielectric. Kansal et al [5] have carried out investigation on PMEDM of MMCs adding silicon carbide, aluminium, copper, and chromium powders into dielectric and reported that increase in the MRR as well as a decrease in tool wear. Kung et al.[6] have reported increase in machining efficiency when Al powder particles were mixed in dielectric during electrical discharge machining of cobalt-bonded tungsten carbide. Sanjeev kumar et al.[7] have noticed that the changes in surface properties of OHNS die steel after machining with manganese powder mixed into kerosene dielectric medium. It was observed from the results that improvement in Vickers microhardness and no micro cracks on the machined surface. Mai et al.[8] have investigated the effect of adding carbon nano tubes (CNT) in dielectric on the surface integrity of the work piece and the machining efficiency. Behzad Jabbaripour et al.[9] performed powder mixed electrical discharge machining (PMEDM) of titanium alloy by means of different powders such as aluminium, chrome, silicon carbide, graphite and iron to investigate the output characteristics of surface roughness topography, material removal rate (MRR) and electrochemical corrosion resistance of machined 
samples. Vikram Reddy V et al.[10] has reported the influence of surfactant and graphite powder mixed dielectric fluid on responses such as MRR, SR, WLT and SCD during EDM of PH17-4 steel.

It was observed from the available literature that mixed powder particles into the dielectric fluid create higher discharge probability that facilitate ignition process causing decrease in breakdown strength of dielectric fluid resulting into increasing in sparking efficiency. Inter electrode gap distance increases due to mixing of conductive powders into dielectric medium, that reduces energy per spark and more uniform distribution of the discharges throughout the surface and ploughing effect of powder particles resulting in decrease in Recast layer thickness and micro cracks, also substantial improvement in corrosion resistance can be achieved on the machined surface. A number of researchers have conducted experiments to know the effects of various powders with different proportions, grain sizes, and powder properties like density, electrical resistivity, thermal conductivity and other process conditions.

EDM is also being increasing used to machine wide variety of exotic, high strength, high temperature and corrosion resistant and difficult to machine alloys used in aerospace and automobile industries. One such material is nickel super alloy RENE80 which is gaining importance because of its wide usage. RENE80 nickel alloy possesses high hardness, high strength and creep properties combined with corrosion resistance and oxidation at high temperatures. Manufacturing of turbine blades and engine parts of high speed fighter planes, RENE80 nickel alloy is widely used. The demand of high quality components is due to hot sections of gas turbines which are subjected to high mechanical and thermal stresses in the service. Due to its low thermal conductivity, high hardness and high resemblance to react with the cutting materials during machining when high temperatures generated, it is not easy to machine RENE 80. Hence it may require non-traditional machining methods to cut this super alloy. Among the non-traditional machining processes, EDM is perhaps the most popular one and adopted by manufacturing industries. Hence it is essential to know the features of electric discharge machining of RENE80 alloy. Still, the available research data in the form of published work pertaining to EDM of RENE80 nickel super alloy is very little. In this study, experiments are conducted to explore the formation of RLT and surface integrity during EDM of RENE80 nickel super alloy with various powders by varying concentrations mixed into the dielectric fluid.

\section{Experimentation}

In the present work, experiments were carried out by varying the powders concentration namely aluminium, graphite and combination of aluminium and graphite in the dielectric medium. Optimal combination of EDM input parameters such as pulse on time, peak current, and pulse off time values obtained by conducting preliminary experimentation on work material and were kept unchanged during experimentation. For conducting experiments RENE80 nickel super alloy was chosen as work material and is cut into size of $70 \times 35 \times 4 \mathrm{~mm}^{3}$ by wire cut EDM process. The composition of RENE80 nickel alloy is presented in Table 1. Physical and Mechanical properties of RENE80 are presented in Table 2. Tool electrode material, electrolyte copper of 14 $\mathrm{mm}$ diameter and $70 \mathrm{~mm}$ length was selected for conducting experiments and its properties were shown in Table 3.

Table 1: Elemental composition of RENE 80 nickel super alloy (wt \%)

\begin{tabular}{|l|l|l|l|l|l|l|l|l|l|l|l|l|l|l|}
\hline Element & $\mathrm{Al}$ & $\mathrm{C}$ & $\mathrm{W}$ & $\mathrm{Mo}$ & $\mathrm{Ti}$ & $\mathrm{Si}$ & $\mathrm{Cr}$ & $\mathrm{Fe}$ & $\mathrm{Ce}$ & $\mathrm{Co}$ & $\mathrm{Mn}$ & $\mathrm{B}$ & $\mathrm{Ni}$ \\
\hline \multirow{3}{*}{ Weight $\%$} & 5 & 0.13 & 4.5 & 3.5 & 2.5 & & 9.5 & 0.5 & & 4 & & 0.02 & \\
& - & - & - & - & - & $<0.4$ & - & $\mathrm{m}$ & \\
& 6 & 0.2 & 5.5 & 4.8 & 3.2 & & 12 & $\max$ & & $4.015 \mathrm{max}$ & - & $<0.4$ & $\mathrm{max}$ & Balance \\
\hline
\end{tabular}

Table 2: Mechanical and physical properties of RENE 80 nickel alloy

\begin{tabular}{|l|l|}
\hline Work Material & RENE 80 Nickel Super Alloy \\
\hline Hardness $(\mathrm{HRC})$ & $43-45$ \\
\hline Ultimate tensile strength $\left(\mathrm{Kg} / \mathrm{mm}^{2}\right)$ & 85 \\
\hline Electrical resistivity $\mathrm{n} \Omega$ & 1300 \\
\hline Thermal conductivity $\left(\mathrm{W} / \mathrm{m}^{\circ} \mathrm{K}\right)$ & 11.5 \\
\hline Melting range $\left({ }^{\circ} \mathrm{C}\right)$ & $1320-1380$ \\
\hline Density $\left(\mathrm{g} / \mathrm{cm}^{3}\right)$ & 8.16 \\
\hline Elongation \% & 3 \\
\hline Reduction in Area \% & $5-7$ \\
\hline Creep strength $\left({ }^{\circ} \mathrm{C}\right)$ & 975 \\
\hline Creep rupture $\left(\mathrm{Kg} / \mathrm{mm}^{2}\right)$ & 25 \\
\hline
\end{tabular}

Table 3: Physical properties of electrolyte copper

\begin{tabular}{|l|l|}
\hline Specific capacity & $383\left(\mathrm{~J} / \mathrm{kg}{ }^{\circ} \mathrm{C}\right)$ \\
\hline Density & $8.95\left(\mathrm{~g} / \mathrm{cm}^{3}\right)$ \\
\hline Melting point & $1083^{\circ} \mathrm{C}$ \\
\hline Thermal conductivity & $394\left(\mathrm{~W} / \mathrm{m}^{\circ} \mathrm{C}\right)$ \\
\hline Electrical resistivity & $1.673 \times 10^{-8} \Omega \mathrm{m}$ \\
\hline
\end{tabular}


The EDM oil grade SAE450 was used as dielectric medium for experimentation. All the experiments were conducted on die sinking FORMATICS 50 EDM which contains controller ELECTRONICA PRS 20 and customized working medium circulating system has been intended for conducting experiments. In custom-made system, for better flow of powders which are mixed into the medium, a micro pump is incorporated. A motorized stirrer system is also installed to avoid settling of powder substances. The customized experimental setup is given in Fig 1.

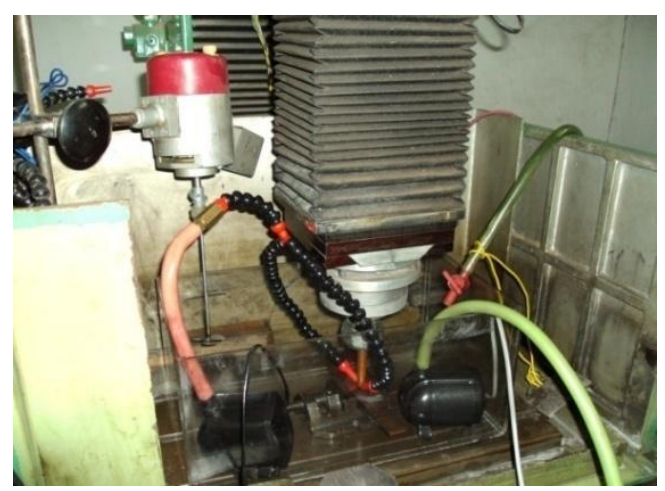

Figure1: Modified experimental set up

Each experiment was conducted thrice to reduce the experimental error and average value is considered for analysis. The time for machining chosen for each experiment is 3 minutes. Many trials were conducted for machining of Nickel based alloy and in 3 minutes the results were obtained after machining and found to be very small variation within the results. Hence 3 minutes machining time is chosen. Various powders namely aluminium, graphite and combination of aluminium and graphite are chosen based on the literature review and also from preliminary investigations, for mixing into the dielectric medium for conducting experiments by varying each powder concentration separately. The physical properties of $\mathrm{Al}$ and graphite powders are shown in Table 4.

Table 4: Properties of $\mathrm{Al}$ and Graphite powders

\begin{tabular}{|l|l|l|}
\hline Properties & Aluminium Powder & Graphite powder \\
\hline Thermal conductivity & $237\left(\mathrm{~W} / \mathrm{m}^{\circ} \mathrm{k}\right)$ & $3000\left(\mathrm{~W} / \mathrm{m}^{\circ} \mathrm{k}\right)$ \\
\hline Electrical resistivity & $0.377\left(\mu \Omega-\mathrm{cm}^{-1}\right)$ & $0.003\left(\mu \Omega-\mathrm{cm}^{-1}\right)$ \\
\hline Density & 2.37 to $2.68\left(\mathrm{~g} / \mathrm{cm}^{3}\right)$ & 1.80 to $2.10\left(\mathrm{~g} / \mathrm{cm}^{3}\right)$ \\
\hline Particle size & 20 to $30 \mu \mathrm{m}$ & 20 to $30 \mu \mathrm{m}$ \\
\hline Melting Point & $660.32^{\circ} \mathrm{C}$ & $3419-3424^{\circ} \mathrm{C}$ \\
\hline
\end{tabular}

The present work focused on to identify the consequences of the above powders and their concentrations on EDM feature Recast Layer Thickness. The electrodes and work pieces were cleaned and polished before machining. The preferred investigational conditions are presented in the Table 5.

Table 5: Conditions for experiments

\begin{tabular}{|l|l|}
\hline Work piece & $70 \mathrm{~mm} \mathrm{X} \mathrm{35mm} \mathrm{X4mm}$ \\
\hline Electrode & Electrolyte copper tool (14mm diameter ) \\
\hline Dielectric Medium & Commercial EDM Oil grade SAE 450+ powder \\
\hline Polarity & Positive \\
\hline Flushing & Side flushing with pressure $0.5 \mathrm{MPa}$ \\
\hline Gap voltage & $70 \mathrm{~V}$ \\
\hline Supply voltage & $110 \mathrm{~V}$ \\
\hline Pulse on time & $65 \mu \mathrm{s}$ \\
\hline Peak current & $20 \mathrm{~A}$ \\
\hline Pulse off time & $48 \mu \mathrm{s}$ \\
\hline Machining time & $3 \mathrm{minutes}$ \\
\hline
\end{tabular}

To find the RLT, the machined samples were cut into perpendicular to the machined surface by wire cut EDM and polished with silicon carbide papers of grades $1 / 0,2 / 0,3 / 0,4 / 0 \& 8 / 0$ and subsequently by applying diamond paste samples were polished on double disc grinder. In order to render the Recast layer formation and boundary line, Kallings reagent etchant $\left(\mathrm{HCl}(100 \mathrm{ml})+\mathrm{CuCl}_{2}(5 \mathrm{ml})+\right.$ ethanol $\left.(100 \mathrm{ml})\right)$ was applied on the polished surface for 1 minute. Then it was dried up after cleaning with water. Scanning electron microscope (SEM) was used for the analysis of Recast layer. The thickness of recast layer has been measured by taking the average of 5 values measured at different points with the Image analyzer software. Further SEM micrographs

DOI: $10.9790 / 1684-1403044350 \quad$ www.iosrjournals.org $\quad 45 \mid$ Page


are taken on machined surface to analyse surface morphology after machining. EDAX analysis has been done in RLT zone to find the presence of various elements in the RLT

\section{Results And Discussion}

Table 6 presents average values of RLT with varying aluminium powder concentration. Table 7 shows response value with varying graphite powder concentration. Table 8 presents response value with varying combination of aluminium and graphite powder concentration (1:1ratio).

Table 6: RLT values with varying Al powder concentration

\begin{tabular}{|l|l|}
\hline Al powder concentration $(\mathrm{g} / \mathrm{l})$ & $\mathrm{RLT}(\mu \mathrm{m})^{*}$ \\
\hline 0 & 44.63 \\
\hline 4.5 & 18.83 \\
\hline 9 & 14.42 \\
\hline 14 & 26.13 \\
\hline
\end{tabular}

Table 7: RLT values with varying Graphite powder concentration

\begin{tabular}{|l|l|}
\hline Graphite powder concentration $(\mathrm{g} / \mathrm{l})$ & $\mathrm{RLT}(\mu \mathrm{m})^{*}$ \\
\hline 0 & 44.63 \\
\hline 4.5 & 28.79 \\
\hline 9 & 41.37 \\
\hline 14 & 42.39 \\
\hline
\end{tabular}

Table 8: RLT values with varying combination of $\mathrm{Al}$ and Graphite powder (1:1 ratio) concentration

\begin{tabular}{|l|l|}
\hline $\mathrm{Al}+$ graphite powder concentration $(\mathrm{g} / \mathrm{l})$ & $\mathrm{RLT}(\mu \mathrm{m})^{*}$ \\
\hline 0 & 44.63 \\
\hline 4.5 & 15.41 \\
\hline 9 & 20.10 \\
\hline 14 & 31.05 \\
\hline
\end{tabular}

*Average of Five values

1. Effect of Powders and their Concentrations on RLT: The variation of RLT with various powders and their concentrations is shown in Fig 2. Comparison of RLT values at different powders and their concentrations is presented in Figure 3. It is observed from the Fig 2 that RLT decreases when powder substances added into dielectric medium. It is noticed that, RLT decreases with increasing in aluminium powder from 0 to $9 \mathrm{~g} / 1$ then it increases further increasing in Al powder substance from 9 to $14 \mathrm{~g} / 1$. However RLT decreases with increasing in graphite as well as combination of $\mathrm{Al}$ and graphite powders (1:1 ratio) from 0 to $4.5 \mathrm{~g} / \mathrm{l}$. Further, it is observed that increase of RLT with increment of graphite as well as combination of Al and graphite powders (1:1 ratio) from 4.5 to $14 \mathrm{~g} / 1$.

The experimental results presented show that the RLT is decreased as powder concentration increases. Further, when powder concentration increases, there will be an insignificant increase in the recast layer thickness. The reason might be the mixing of powder into dielectric medium reducing the breakdown strength of the medium that widens discharge channel gap that improves flushing efficiency resulting into reduced recast layer. As further increase in powder concentration into the dielectric fluid makes unstable discharge resulting into increased recast layer thickness.

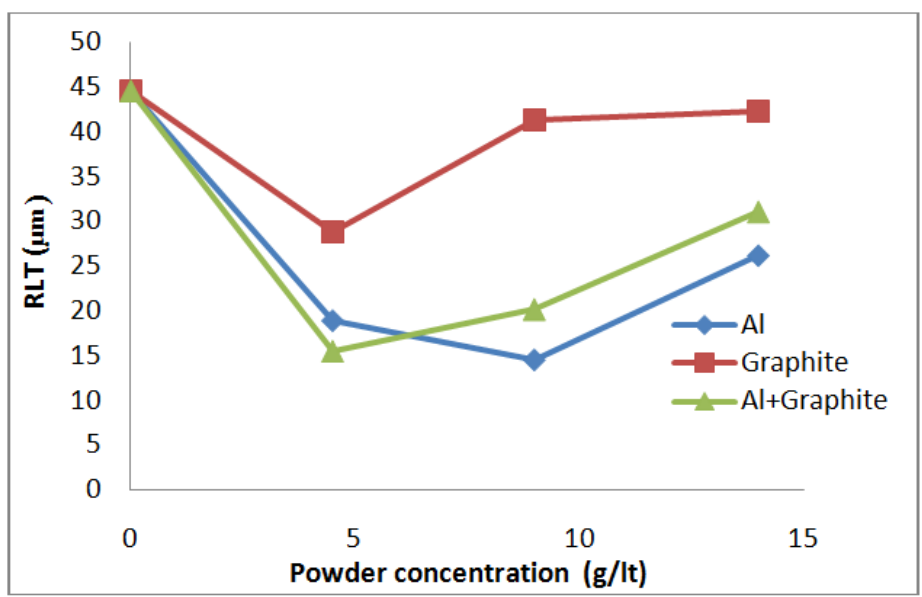

Figure 2: Variation of RLT with powder concentration 


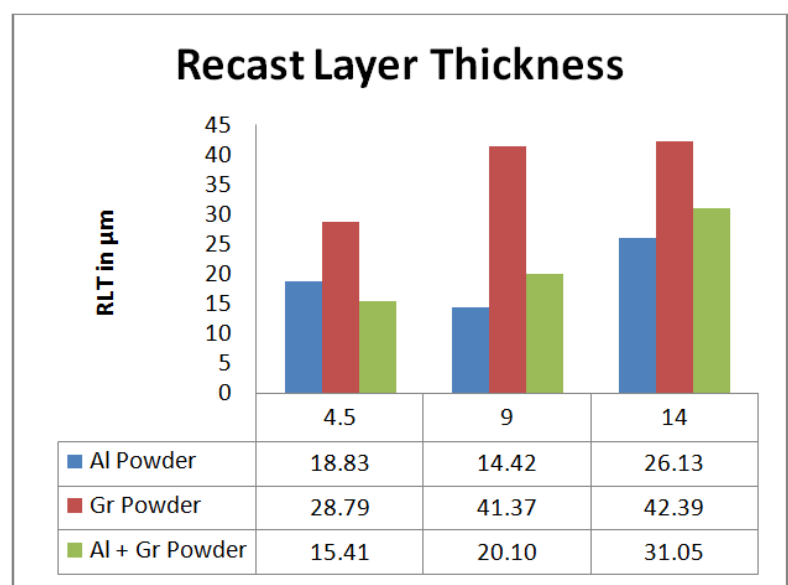

Figure 3: Comparison of RLT with powder concentration

It is observed from the Fig 3 that the minimum RLT is achieved at $9 \mathrm{~g} / \mathrm{l}$ of Aluminium powder. The reason might be due to high density, low thermal conductivity and melting point of aluminium powder when compare with graphite powder. Fig 4 shows the SEM images of Recast Layer Thickness with different powders and their concentrations.

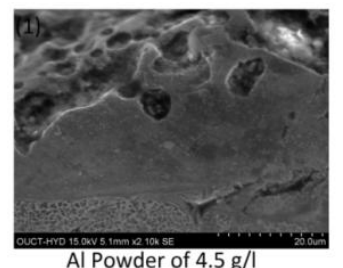

Al Powder of $4.5 \mathrm{~g} / \mathrm{l}$
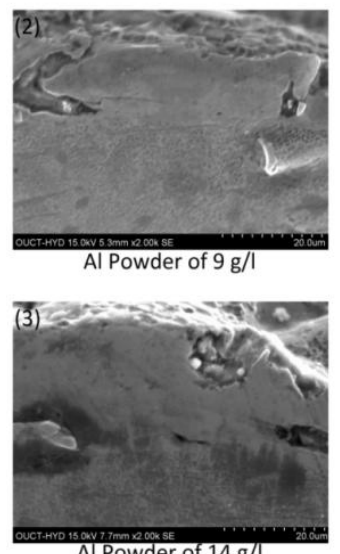

AlPowder of $14 \mathrm{~g} / \mathrm{l}$

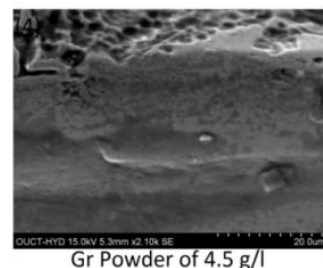

Gr Powder of $4.5 \mathrm{~g} / \mathrm{l}$

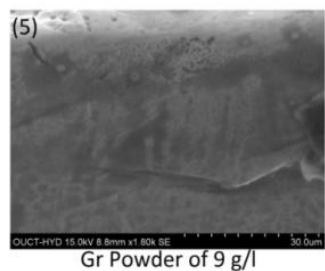

Gr Powder of $9 \mathrm{~g} / \mathrm{l}$

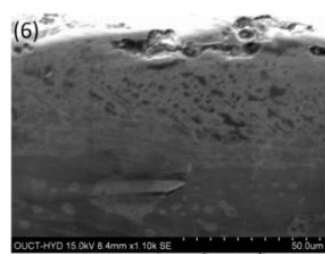

Gr Powder of $14 \mathrm{~g} / \mathrm{l}$

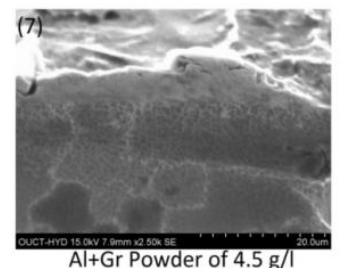

Al+Gr Powder of $4.5 \mathrm{~g} / \mathrm{l}$
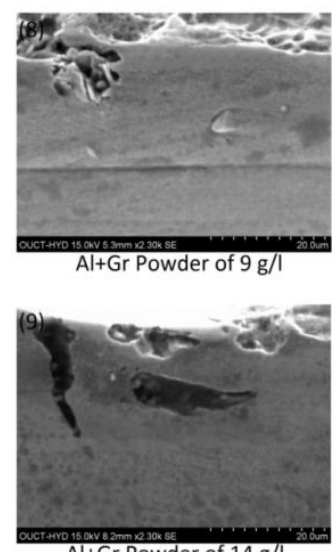

Al+Gr Powder of $14 \mathrm{~g} / \mathrm{l}$

Figure 4: SEM Micrographs for RLT

\section{Surface Topographical Analysis of Machined Surfaces:}

2.1. SEM Analysis: Further analysis of machined surfaces was performed after conducting experiments to observe surface topography using Scanning Electronic Microscope (SEM) images at 200X magnification. These images are shown in Fig 5. It is noticed that all machined surfaces contain appendages, craters, debris globules, voids and cracks and their extent is varying. Presence of all above causes for poor surface finish. Comparing the SEM images in fig 5 (serial number 1 to 9) clearly indicates that with increase of powder concentration into the dielectric medium, crater depth and diameter are increasing hence the surface roughness also increases. The increased crater depth and diameter also noticed when graphite powder mixed into the dielectric. Another observation is that thick appendages were found around the periphery of crater from micrographs of serial number 4,5 and 8 this may be due to resolidified molten metal. It is also observed from micrographs of serial number 2, 3, 4, 5, 8 and 9 that appendages formed due to the solidification of molten metal which flows over the machined surface. Because of more molten metal removed from the crater and suspended in the little gap between electrodes, large appendages and denser of debris can be seen in micrographs of serial 
number 3, 5 and 8 . This may be the result of more concentration of powders which were mixed into dielectric fluid.

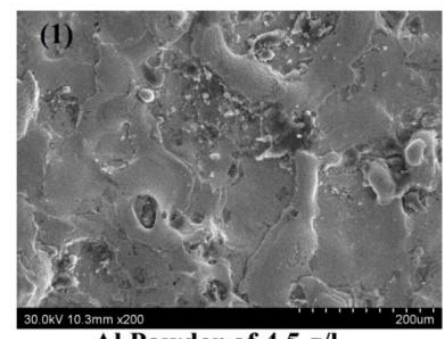

Al Powder of $4.5 \mathrm{~g} / \mathrm{l}$

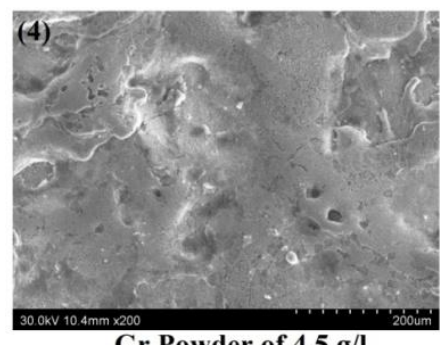

Gr Powder of $4.5 \mathrm{~g} / \mathrm{l}$

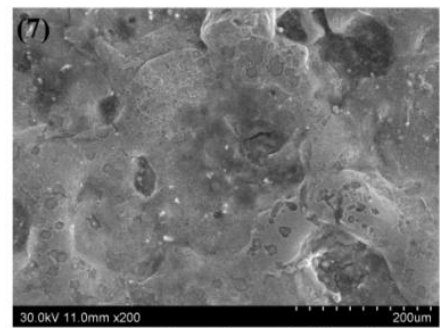

Al + Gr Powder of $4.5 \mathrm{~g} / \mathrm{l}$

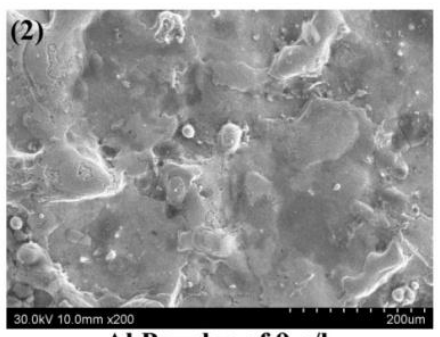

Al Powder of $9 \mathrm{~g} / \mathrm{l}$

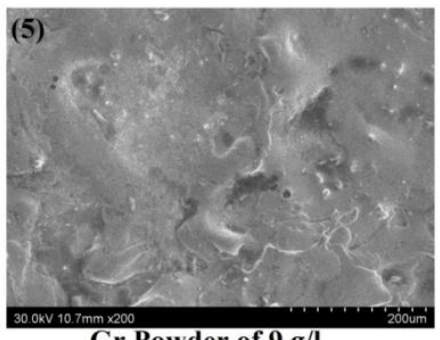

Gr Powder of 9 g/l

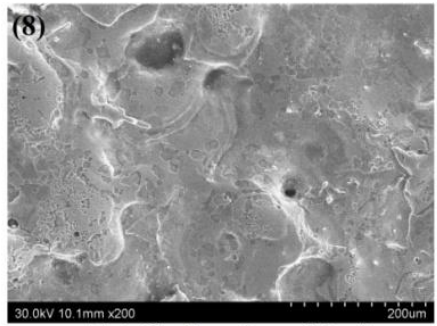

Al + Gr Powder of 9 g/l

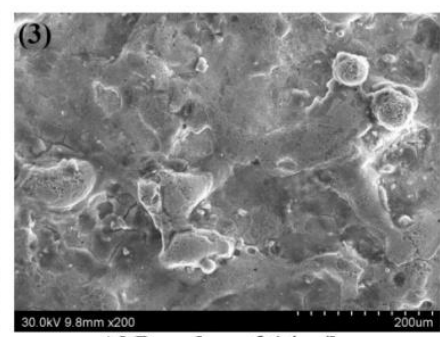

Al Powder of $14 \mathrm{~g} / \mathrm{l}$

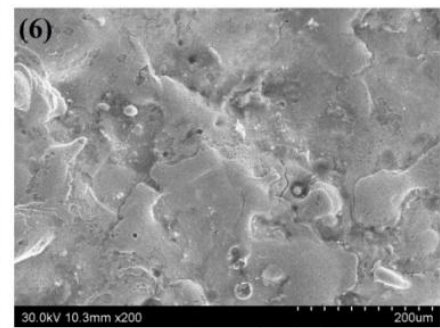

Gr Powder of $14 \mathrm{~g} / \mathrm{l}$

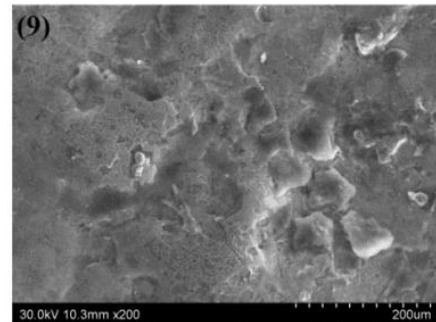

Al + Gr Powder of 14 g/l

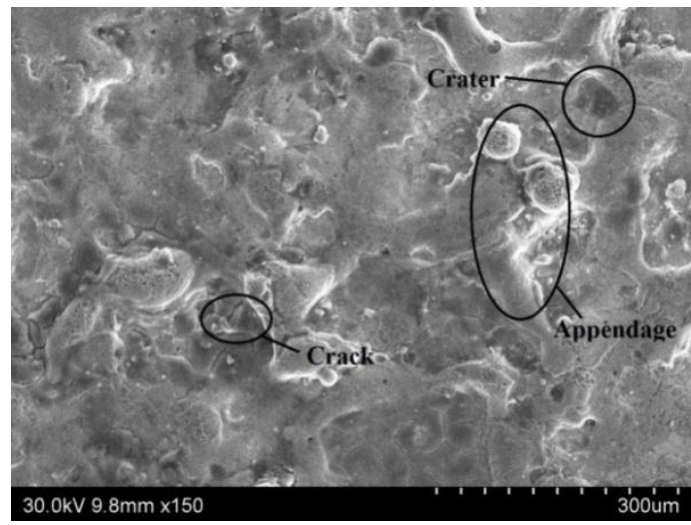

Figure 5: SEM images of surface morphology (200 X) of PMEDM machined surfaces

It was also observed that varying sizes of pockmarks and pinholes on machined surfaces from micrographs of serial number 2, 3, 6 and 8. These may be formed as a result of burst of gases like $\mathrm{CO}, \mathrm{CO}_{2}$ and $\mathrm{H}_{2}$ which may try to run away from machined surface. The reason might be with increase in temperature and decrease in solubility of these gases in dielectric medium. These are the immobility products formed due to oxidation and decomposition of aliphatic hydrocarbons in medium at elevated temperatures during machining. While conducting the experiments typical smell was felt and also visualised the generation of gas bubbles.

Formation of cracks with different size and density is another feature of electrical discharge machined surface. These cracks formation is owing to the thermal stresses exceed the tensile strength of this alloy which is generated during machining. This thermal stress cracking is represented in the form of narrow cracks on the surface (micrographs of serial number 3, 4, 6, 7 and 9). The surface cracking formation also might be the reason to some extent due to the presence of cobalt because it has high thermal coefficient of expansion as compared to other metals which leads to low thermal conductivity of this alloy. 
2.2. EDAX Analysis: In EDM machining, high temperatures are produced due to localized heating causing melting of work material instantly and even vaporize. This causes complex chemical reactions between work piece and electrode through dielectric. Attempt is being made to measure the chemical compositions of selected machined samples by conducting the EDAX test and is presented in Fig 6. Further comparison of the elemental analysis is done at maximum MRR and minimum SR and RLT conditions of various powders and their concentrations.

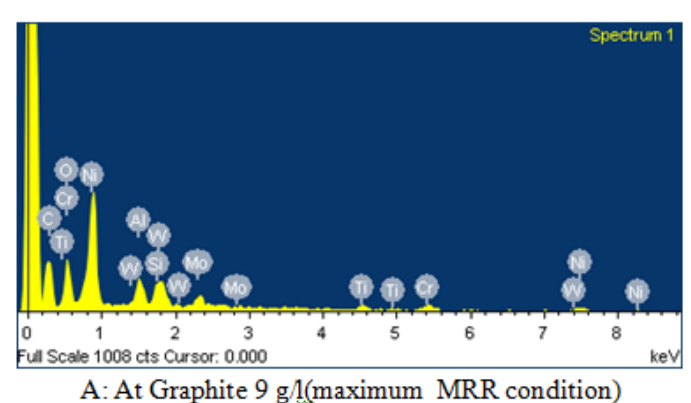

A: At Graphite $9 \mathrm{~g} /$ (maximum MRR condition)

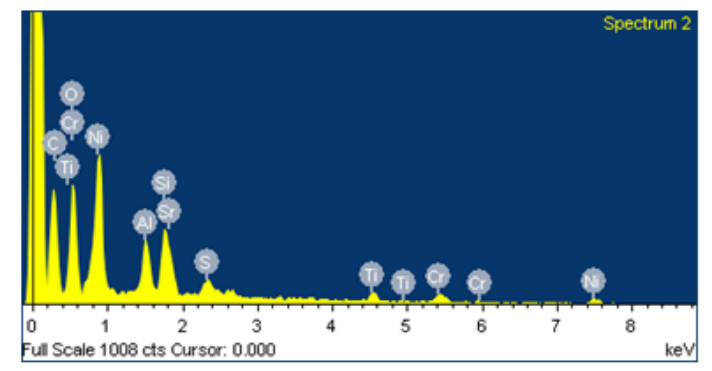

$\mathrm{B}$ : At Al+Graphite $4.5 \mathrm{~g} /$ (minimum SR condition)

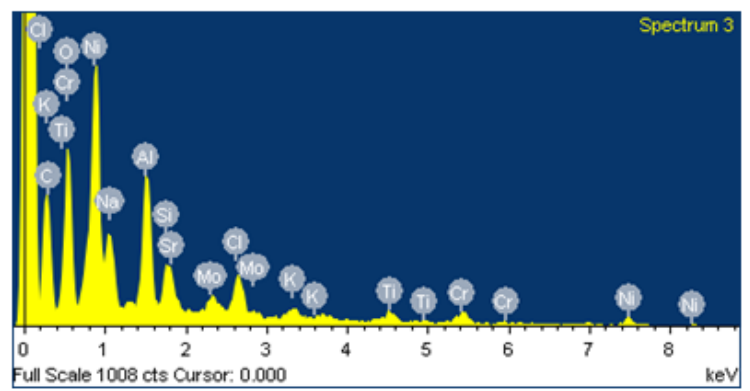

Figure 6: EDAX Analysis of selected electrical discharge machined samples

It is noticed that there is no copper element present in all three spectra which indicates that the electrode particles (copper) were not transferred on to the machined surface. It is also observed from the EDAX images that the presence of oxygen and carbon elements at different levels, this may be due to the decomposition of dielectric fluid into Carbon, Hydrogen and Oxygen. These decomposed elements are deposited into the molten metal during discharge. It is also seen on all machined surfaces that black and tiny carbon particles during experimentations. The comparison of some of the important elements at RLT conditions of various powders and their concentrations is shown in table 9.

Table 9: Relative weight \% of important elements at minimum RLT condition

\begin{tabular}{|l|l|l|l|l|}
\hline Element & At unmachined surface & At Al+Graphite 4.5g/l & At Graphite 4.5 g/l & At Al 9 g/l \\
\hline Carbon & 0.2 & 26.31 & 24.77 & 13.60 \\
\hline Oxygen & 3.1 & 15.04 & 11.35 & 5.44 \\
\hline Nickel & 58.27 & 29.05 & 33.09 & 56.55 \\
\hline Aluminium & 5.16 & 3.04 & 4.95 & 5.27 \\
\hline Titanium & 2.36 & 2.92 & 2.17 & 2.65 \\
\hline Chromium & 8.86 & 13.69 & 15.66 & 6.20 \\
\hline
\end{tabular}

It is noticed from the Table 9 that the increased amount of carbon is present on machined samples. This may be due to the deposition of carbon into molten metal. This carbon was obtained from decomposition of dielectric fluid during machining.

\section{Conclusions}

The following conclusions were made from this work:

1. The decrease in RLT was observed with mixing of powders into dielectric medium.

2. The trend of RLT was decreased with increase in powder concentration into the dielectric medium.

3. The minimum RLT $(14.42 \mu \mathrm{m})$ is obtained at $9 \mathrm{~g} / \mathrm{l}$ concentration of aluminium powder.

4. The presence of oxygen and carbon elements at different percentages, were found on all machined surfaces. This may be due to the decomposition of dielectric fluid into Carbon, Hydrogen and Oxygen. These decomposed elements are deposited into the molten metal during discharge. 


\section{References}

[1] Erden A and Bilgin S. Role of impurities in electrical discharge machining. In: 21th International Machine Tool Design and Research Conference, Macmillan, London, 1980, pp. 345-350.

[2] Guo ZN, Lee TC, Yue TM, et al. A study of ultrasonic aided wire electrical discharge machining. J. Mater. Process. Technol 1997;63:823-828.

[3] Zhao WS, Meng QG and Wang ZL. The application of research on powder mixed EDM in rough machining. J. Mater. Process. Technol 2002;129:1-3:30-33.

[4] Singh S, Maheshwari S and Dey A. Electrical discharge machining (EDM) of aluminium metal matrix composites using powdersuspended dielectric fluid, J. Mech. Eng. 2006;57:5:271-290.

[5] Kansal HK, Singh S and Kumar P. An experimental study of the machining parameters in powder mixed electric discharge machining of Al-10\%SiCP metal matrix composites, Int. J. Manuf. Technol. Manag. 2006;1:4:396-411.

[6] Kung KY, Horng JT and Chiang KT. Material removal rate and electrode wear ratio study on the powder mixed electrical discharge machining of cobalt-bonded tungsten carbide, Int. J. Adv. Manuf. Technol. 2009; 40:95-104.

[7] Sanjeev Kumar and Rupinder Singh. Investigating surface properties of OHNS die steel after electrical discharge machining with manganese powder mixed in the dielectric, Int. J. Adv. Manuf. Technol. 2010. DOI :10.1007/s00170-010-2536-3.

[8] Mai C. et al., Advantages of carbon nanotubes in electrical discharge machining. Int. J. Adv. Manuf. Technol. 2012; 59:111-117.

[9] Behzad Jabbaripour, Mohammad Hossein Sadeghi, Mohammed Reza Shabgard. et al. Investigating surface roughness material removal rate and corrosion resistance in PMEDM of $\gamma$-TiAl intermetallic. J. Manuf. Processes 2013;15:1:56-68.

[10] Vikram Reddy V, Kumar A, Madar Valli. P. et al. Influence of surfactant and graphite powder concentrationon electrical discharge machining of PH17-4 stainless steel, J. Braz. Soci. of Mech. Scie. and Eng. 2014. ISSN 1678-5878. DOI: 10.1007/s40430-0140193-4. 